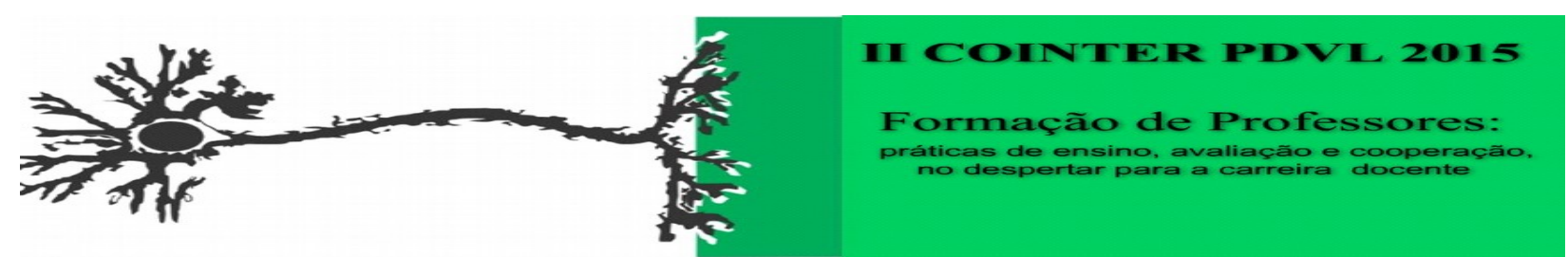

\title{
A EXTENSÃO UNIVERSITÁRIA COMO INSTRUMENTO DE COOPERAÇÃO INTERINSTITUCIONAL: A EXPERIÊNCIA DOS CURSOS DE FORMAÇÃO CONTINUADA DO PROGRAMA DESPERTANDO VOCAÇÕES
}

\author{
Apresentação: Pôster
}

\begin{abstract}
Anderson de Assis Silva; Artur da Silva Coêlho ; Kaline Soares da Silva ; Francisca Maria Silva Miranda; Edísio Raimundo Silva; Erick Viana da Silva
\end{abstract}

\section{Introdução}

Esse trabalho tem como objetivo descrever e analisar a experiência dos cursos de formação continuada do Programa Despertando Vocações (PDV) no âmbito da cooperação interinstitucional. A pesquisa é de natureza aplicada, através de um estudo de caso com abordagem qualitativa e utilizou procedimentos de pesquisa bibliográfica e documental. Como resultados verificamos que a formação de redes de cooperação nas práticas extensionistas analisadas, os cursos de formação continuada, potencializaram a utilização dos recursos e provocaram ações sinérgicas com benefícios para todos os atores envolvidos. Outra característica denotada foi o empoderamento de servidores, estudantes e comunidades envolvidas com pouca intervenção junto aos protagonistas por parte de agentes políticos e de gestão institucional, corroborando para uma prática inovadora de fazer extensão partindo das necessidades percebidas pela comunidade e construção de soluções criativas.

\section{Fundamentação Teórica}

A construção de novas realidades que aproveitem o capital humano, pode propiciar o desenvolvimento de novas competências requeridas e propiciar o alcance da missão, ou no caso do setor público, a função social da instituição. A partir de tais constatações, decidimos realizar um estudo de caso de um destes grupos, a fim de evidenciar 
elementos de um "território" organizacional objetivo, nessa perspectiva, ainda inexplorado sob a luz da teoria institucional: as redes de cooperação no campo da extensão no âmbito dos Institutos Federais, mais especificamente o Programa Internacional Despertando Vocações. A teoria institucional, basicamente, põe no centro das discussões a legitimidade da organização e a tendência ao isomorfismo. A organização deve ser vista interagindo, contextualizando o ambiente para melhor entender as tomadas de decisões. No entanto, as organizações agem dentro do contexto nos quais estão inseridas modelando-os também. Essa corrente multilateral de interações, envolvendo valores, crenças, mitos, ética leva à necessidade de agregar aos valores econômicos, de recursos humanos e logísticos, valores culturais. (SILVA,2013)

O Programa de Extensão Internacional Despertando Vocações para as Licenciaturas (PDVL) foi uma experiência piloto, inspirada em projeto semelhante destinado às carreiras das áreas tecnológicas e engenharias conduzidas pela Universidad de Mendoza (UM) e participação do Instituto Federal de Pernambuco (IFPE) no ano de 2013 e que deu prosseguimento em 2014 e 2015 conduzido por servidores do IFPE - Campus Vitória de Santo Antão. Tem o objetivo de desenvolver ações que auxiliem no despertar do interesse de estudantes do Ensino Médio para os cursos de Licenciaturas e incentivar a carreira docente dos licenciandos dessas áreas, através da articulação de atividades de ensino, pesquisa e extensão e da troca de saberes entre a Academia e a Escola Básica, utilizando-se do formato de Rede de Cooperação Internacional. Com sua execução e êxito entre os anos de 2013 a 2015 houve a ampliação de seu escopo e desdodramento de sua estrutura organizacional e de parcerias.

Dessa maneira surgiu o Programa Internacional de Gestão e Cooperação Despertando Vocações (PDV), responsável pela formação de Redes de Cooperação e que apoia e subsidia as ações do PDVL e PDVAGRO. São compostos por dois projetos cada um: (P1), que buscam colaborar com a criação de interfaces de comunicação entre os cursos de Licenciatura/Ciências Agrárias das instituições participantes e (P2) que objetiva criar e fortalecer redes de cooperação nas áreas de ensino, pesquisa, extensão e gestão das instituições parceiras nas áreas específicas de cada PDV(Licenciaturas/Ciências Agrárias). Pretende-se, respeitando as peculiaridades de cada região e participante, gerar um fio condutor que possa congregar as potencialidades criativas de cada parceiro na solução de desafios comuns. No caso específico a atração e manutenção do interesse dos 
estudantes dos anos finais do Ensino Fundamental pelas ciências agrárias e do Ensino Médio pelas licenciaturas..

\section{Metodologia}

A pesquisa é de natureza aplicada, através de um estudo de caso único com abordagem qualitativa e utilizou nos procedimentos as pesquisas, bibliográfica. O Campo de pesquisa envolve os parceiros que interagiram na área de cursos presenciais de formação dentro do PDV no período compreendido entre Fevereiro a Outubro de 2015.

\section{Resultados e Discussões}

Os cursos de formação continuada do PDV consistem em duas categorias distintas, os cursos presenciais e aqueles ministrados na modalidade de Ensino a Distância (EaD) com a participação de entes internacionais, neste estudo o foco encontra-se, apenas, naqueles de natureza presencial. Os cursos são elencados e definidos preliminarmente na etapa do planejamento anual de ações com vistas a subsidiar os participantes e as comunidades atendidas de elementos teórico-práticos necessários ao alcance dos objetivos do PDV e/ou satisfação de necessidades das comunidades atendidas.

Elenca-se no quadro 1 - Cursos PDV 2015, os cursos ofertados, os segmentos atendidos, instituições ministrantes e participantes, custos envolvidos, resultados obtidos.

Quadro 1- Cursos PDV 2015

\begin{tabular}{|c|c|c|c|c|c|}
\hline Curso & Público & $\begin{array}{l}\text { Instituição } \\
\text { Ministrante }\end{array}$ & $\begin{array}{l}\text { Instituição } \\
\text { Atendida }\end{array}$ & Objetivo & Resultado \\
\hline Introdução ao Moodle & $\begin{array}{l}\text { Estudantes } \\
\text { e } \\
\text { professores }\end{array}$ & $\begin{array}{l}\text { Prefeitura } \\
\text { Municipal de } \\
\text { Vitória - PDVL }\end{array}$ & $\begin{array}{l}\text { IFPE - Campus } \\
\text { Vitória }\end{array}$ & $\begin{array}{l}\text { Capacitar extensionistas para } \\
\text { atuação junto ao Ambiente } \\
\text { Virtua de Aprendizagem }\end{array}$ & 10 pessoas \\
\hline $\begin{array}{l}\text { Planejamento e Introdução } \\
\text { ao Gerenciamento de } \\
\text { Projetos }\end{array}$ & Estudantes & $\begin{array}{l}\text { IFPE - Campus } \\
\text { Recife }\end{array}$ & $\begin{array}{l}\text { IFPE Campus } \\
\text { Vitória }\end{array}$ & $\begin{array}{l}\text { Capacitar extensionista } \\
\text { acerca das boas práticas de } \\
\text { gerenciamento de projetos }\end{array}$ & 25 pessoas \\
\hline Oratória & Estudantes & $\begin{array}{l}\text { IFPE - Campus } \\
\text { Paulista }\end{array}$ & $\begin{array}{l}\text { IFPE - Campus } \\
\text { Vitória }\end{array}$ & $\begin{array}{l}\text { Capacitar extensionistas } \\
\text { acerca de técnicas de oratória } \\
\text { e comunicação }\end{array}$ & 18 pessoas \\
\hline Redes e Formação política & Estudantes & IFPE - Campus & IFPE Campus & Discutir a formação das ligas & 50 pessoas \\
\hline
\end{tabular}




\begin{tabular}{|c|c|c|c|c|c|}
\hline & $\begin{array}{l}\text { do PDV } \\
\text { ecomunida } \\
\text { de em geral }\end{array}$ & $\begin{array}{l}\text { Vitória e ONG } \\
\text { Brasil-Mirim }\end{array}$ & Vitória & $\begin{array}{lrr}\text { camponesas } & \text { na } & \text { região } \\
\text { Vitória } & \text { e } & \text { seus } \\
\text { desdobramentos } & & \end{array}$ & \\
\hline Avaliação da Experiência & $\begin{array}{l}\text { Estudantes } \\
\text { do PDVL e } \\
\text { servidores } \\
\text { do IFPE }\end{array}$ & $\begin{array}{l}\text { IFPE - Campus } \\
\text { Vitória }\end{array}$ & $\begin{array}{l}\text { IFPE - Campus } \\
\text { Vitória } \\
\text { estudantes e } \\
\text { docentes }\end{array}$ & $\begin{array}{l}\text { Capacitar a equipe sobre a } \\
\text { base teórica do PDVL no } \\
\text { campo da teoria da avaliação }\end{array}$ & 10 pessoas \\
\hline $\begin{array}{l}\text { Extensão Rural e } \\
\text { Metodologias } \\
\text { Participativas }\end{array}$ & $\begin{array}{l}\text { Servidores } \\
\text { e } \\
\text { estudantes } \\
\text { do IFPE } \\
\text { Campus } \\
\text { Vitória }\end{array}$ & $\begin{array}{l}\text { Sertão } \\
\text { Agroecológico- } \\
\text { UNIVASF }\end{array}$ & $\begin{array}{l}\text { IFPE Campus } \\
\text { Vitória }\end{array}$ & $\begin{array}{l}\text { Bases teórico-práticas da } \\
\text { nova ATER e ferramentas } \\
\text { participativas }\end{array}$ & 28 pessoas \\
\hline $\begin{array}{l}\text { Extensão Rural e } \\
\text { Metodologias } \\
\text { Participativas }\end{array}$ & $\begin{array}{l}\text { Servidores } \\
\text { e } \\
\text { estudantes }\end{array}$ & $\begin{array}{l}\text { IFPE através de } \\
\text { estudantes do } \\
\text { PDVAGRO } \\
\text { capacitados } \\
\text { anteriormente }\end{array}$ & $\begin{array}{l}\text { IFPE Campus } \\
\text { Vitória, Belo } \\
\text { Jardim, } \\
\text { Barreiros, IFPB } \\
\text { - Campus Picuí } \\
\text { e IFSertão } \\
\text { Campus } \\
\text { Petrolina Rural }\end{array}$ & $\begin{array}{l}\text { Bases teórico-práticas da } \\
\text { nova ATER e ferramentas } \\
\text { participativas }\end{array}$ & 30 pessoas \\
\hline $\begin{array}{l}\text { Extensão Rural e } \\
\text { Metodologias } \\
\text { Participativas }\end{array}$ & $\begin{array}{l}\text { Servidores } \\
\text { e } \\
\text { estudantes }\end{array}$ & $\begin{array}{l}\text { IFPE através de } \\
\text { estudantes do } \\
\text { PDVAGRO } \\
\text { capacitados } \\
\text { anteriormente }\end{array}$ & $\begin{array}{l}\text { IFPE Campus } \\
\text { Barreiros na II } \\
\text { Semana de } \\
\text { Agroecologia }\end{array}$ & $\begin{array}{l}\text { Bases teórico-práticas da } \\
\text { nova ATER e ferramentas } \\
\text { participativas }\end{array}$ & 30 pessoas \\
\hline Espanhol para mobilidade & Estudantes & $\begin{array}{l}\text { IFPE Campus } \\
\text { Vitória }\end{array}$ & $\begin{array}{l}\text { IFPE Campus } \\
\text { Vitória }\end{array}$ & $\begin{array}{l}\text { Prepara estudantes para } \\
\text { processo de seleção e } \\
\text { mobilidade internacional }\end{array}$ & 09 pessoas \\
\hline $\begin{array}{l}\text { Introduçaõ ao } \\
\text { empreendedorismo rural }\end{array}$ & Estudantes & $\begin{array}{l}\text { IFPE Campus } \\
\text { Recife }\end{array}$ & $\begin{array}{l}\text { IFPE Campus } \\
\text { Vitória }\end{array}$ & $\begin{array}{l}\text { Preparar tecnicamente } \\
\text { coletivo de estudantes que } \\
\text { desejem empreender na área } \\
\text { rural }\end{array}$ & 16 pessoas \\
\hline $\begin{array}{l}\text { Curso de Cactáceas e } \\
\text { Plantas Ornamentais }\end{array}$ & Estudantes & $\begin{array}{l}\text { IFPB Campus } \\
\text { Picuí }\end{array}$ & $\begin{array}{l}\text { IFPE Campus } \\
\text { Vitória }\end{array}$ & $\begin{array}{l}\text { Prepara tecnicamente } \\
\text { coletivo de estudantes que } \\
\text { desejem empreender na área } \\
\text { de paisagismo. }\end{array}$ & 04 pessoas \\
\hline $\begin{array}{lr}\text { Curso } & \text { de } \\
\text { Georreferenciamento } & \text { e } \\
\text { CAR } & \end{array}$ & $\begin{array}{l}\text { Estudantes } \\
\text { Servidores } \\
\text { e } \\
\text { Comunidad } \\
\text { e }\end{array}$ & $\begin{array}{l}\text { IFPE Campus } \\
\text { Caruaru e PM } \\
\text { de Vitória }\end{array}$ & $\begin{array}{l}\text { IFPE Campus } \\
\text { Vitória e PM } \\
\text { de Vitória }\end{array}$ & $\begin{array}{l}\text { Prepara técnicamente } \\
\text { estudantes que desejem } \\
\text { empreender na área de } \\
\text { georreferenciamento e CAR }\end{array}$ & 14 pessoas \\
\hline TOTAL & & & & & 244 \\
\hline
\end{tabular}

Os atores envolvidos como ministrantes dos cursos de formação presencial do PDV são servidores públicos, municipais, estaduais ou federais que disponibilizam 
voluntariamente por meio de convite feito através de rede de conhecimento e confiança dos participantes. Estes, por sua vez, recebem a certificação relativa à participação no curso. Uma das preocupações do PDV se remete a perenidade do Programa diante das mudanças administrativas que podem gerar descontinuidade de trabalhos que vêm demonstrando resultados positivos. Dessa forma, o fato dos servidores realizarem as capacitações fora de seu horário de expediente, gera liberdade e independência no processo de tomadas de decisão do PDV em relação à temporariedade das gestões institucionais.

\section{Conclusões}

Como o PDV se encontra em andamento, as conclusões são parciais e refletem mais uma expectativa do que números e resultados precisos por si só. No entanto, no período de 10 meses foram realizados presencialmente 12 cursos com a participação direta de participantes de 12 instituições distintas, com preparação de pessoas para atuação como extensionistas. O que foi vivenciado até o momento demonstra que é possível superar os muros da academia e ir além do seu entorno, pois entende-se que o caráter da extensão, em vias da sociedade do conhecimento, deve ser expandido globalmente, inserindo, neste contexto, entes extranacionais como colaboradores e construtores de uma perspectiva da compreensão de soluções locais baseadas em experiências globais. Observamos, assim, que é possível fazer parcerias e trabalhar em equipe. É possível também inserir os extensionistas no planejamento e produção de materiais, auxiliando a formação de estudantes protagonistas.

\section{Referências:}

DA SILVA, Erick Viana. Globalização e Indústria Farmacêutica: para além da saúde, uma questão de mercado. CIENTEC, p. 124. Disponível em http://www.google.com.br/url?

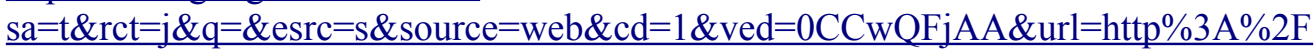
\%2F200.133.17.83\%2Fcientec $\% 2$ Fuserfiles $\% 2$ Ffile $\% 2$ FCIENTEC $\% 25202 \% 2$ Fartigo \%252011.pdf\&ei=zVQ U9k3iKuxBK2agLgD\&usg=AFQjCNFFJPMkIXh6hedodJRTG 35gV Ummg\&bvm=bv.64125504,d.cWc Acesso em 01 de Abril de 2013.

FORINTER, Fórum de assessores de relações internacionais, documento base. 2009. 